\title{
Posterior vitreous detachment following intravitreal drug injection
}

\author{
Ulrich Geck • Nicole Pustolla • Husnia Baraki • \\ Abed Atili • Nicolas Feltgen • Hans Hoerauf
}

Received: 8 May 2012 /Revised: 3 January 2013 / Accepted: 15 January 2013 /Published online: 5 February 2013

(C) The Author(s) 2013. This article is published with open access at Springerlink.com

\begin{abstract}
Background To evaluate the incidence of posterior vitreous detachment (PVD) induced by intravitreal injection of different intravitreal drugs.

Methods This prospective observational study included 61 patients (61 eyes) with different underlying retinal diseases: exudative age-related macular degeneration $(n=47)$, cystoid macular edema (CME) after retinal vein occlusion $(n=8)$, and CME of other origin $(n=6)$. Bevazicumab $(1.25 \mathrm{mg})$ was injected into 25 eyes, ranibizumab $(0.5 \mathrm{mg})$ into 27 eyes, triamcinolone $(4 \mathrm{mg})$ into six eyes, and a combination of bevacizumab and triamcinolone into three eyes. Patients with initial PVD were excluded. Patients were followed for at least 4-6 weeks after their last injection by Fourier-domain OCT, fundus biomicroscopy and ultrasound B-examination.

Results Overall, 15 of 61 eyes developed a PVD after intravitreal injection ( $n=6$ after ranibizumab, $n=7$ after bevacizumab and $n=2$ after triamcinolon) within a mean follow-up period of 11.1 weeks. PVD occurred in three eyes after the first injection, in three eyes after the second, and in seven eyes after the third injection. Incidence of PVD correlated with increasing age.

Conclusion Intravitreal injection of commonly-used drugs seems to induce posterior vitreous detachment, which may thus influence the outcome of the underlying disease.
\end{abstract}

Clinical trial registration As it was an observational study, there has been no clinical trial registration.

U. Geck $(\triangle) \cdot$ N. Pustolla $\cdot$ H. Baraki $\cdot$ A. Atili $\cdot$ N. Feltgen $\cdot$

H. Hoerauf

Augenklinik der Universitätsmedizin Göttingen,

Robert-Koch-Str. 40,

37075 Göttingen, Germany

e-mail: ugeck@web.de
Keywords Vitreous $\cdot$ Intravitreal $\cdot$ Injection $\cdot$ Retina

\section{Introduction}

In the last decade, intravitreal injection has become the most important drug-administration route in several retinal diseases. Studies have shown that the vitreoretinal interface plays a key role in the development of macular pathologies $[4,6,7,11,13,15]$. An attached posterior vitreous cortex is associated with a higher incidence of diabetic macular edema [9], and macular edema has been seen to resolve after spontaneous vitreous detachment. It is reported that surgical posterior vitreous detachment (PVD) is able to reduce macular edema in diabetic maculopathies [5, 16], age-related macular degeneration [8], and retinal vein occlusions [1]. Recent studies have proposed the potential negative influence of attached posterior vitreous hyaloid on the development of exudative age-related macular degeneration $[4,11]$. Thus, efforts were made to identify an intravitreal substance capable of creating posterior vitreous detachment (PVD). A phase II multicenter study demonstrated that microplasmin can induce safe posterior vitreous detachment after intravitreal injection in patients with vitreomacular traction syndromes [14].

It is still unknown whether the intravitreal injection procedure itself using standard intravitreal drugs such as VEGF inhibitors or triamcinolone induces a PVD, and whether there is any correlation to the injected volume or drug. In the control arm of the recently published phase III ocriplasmin study, PVD could be observed by injecting $0.1 \mathrm{ml}$ of a sham-solution in $10.1 \%$ of patients [18].

The aim of this prospective observational study was to evaluate the incidence of posterior vitreous detachment after intravitreal injections of currently-used intravitreal drugs. 


\section{Material and methods}

Inclusion criteria were an attached posterior vitreous membrane and the indication of intravitreal injections for macular disease.

Exclusion criteria were preexisting traction syndromes, former vitrectomy or complicated cataract surgery, and detectable posterior vitreous detachment.

Sixty-one eyes of 61 patients ( 32 female, 29 male) with attached posterior hyaloid were included. Table 1 illustrates the various underlying diseases. Indications for intravitreal injections were exudative age-related macular degeneration $(n=47)$, macular edema caused by retinal vein occlusion $(n=8)$, diabetic macular edema $(n=4)$, cystoid macular edema after cataract surgery $(n=1)$ and uveitis $(n=1)$. The patients' mean age was 72 years $(S D \pm 10.25)$. Demographic data are shown in Table 1. The mean follow-up period was 11.1 weeks. Patients with a history of former intravitreal injections and an attached vitreous (36 patients) were also included in the study, and the number of former injections was recorded. As this circumstance might have an effect on the study outcome, the patient group without previous intravitreal injections and that of patients with former intravitreal injections were evaluated separately.

Patients with a macular hole or an epiretinal membrane were excluded from the study.

\section{Examinations}

Follow-up examinations were performed on the day of the scheduled reinjection. End point of the study was either at detection of posterior vitreous detachment, or at the control visit after a series of injections, usually after three injections (14 weeks), when no further injections were necessary.

To detect whether posterior detachment was present or not, fundus biomicroscopy, ultrasound $\mathrm{B}$ imaging and spectral-domain optical coherence tomography (Cirrus-OCT, Zeiss) were performed (Figs. 1 and 2).
Decision on whether posterior vitreous was attached or not was based on the following criteria:

In fundus biomicroscopy, PVD was assumed only if the Weiss ring was visible. If it was not visible, attached vitreous was assumed, but the other methods were assessed as well and judgement was based on all informations.

In ultrasound-B examination, PVD was assumed, when the posterior vitreous hyaloid was visible and showed no connection to the optic nerve head. In the other cases, vitreous attachment was assumed. See also Fig. 1.

In OCT vitreous attachment was assumed:

- when there was slight or partial detachment visible on the temporal or nasal edge of the scanning area, and the vitreous was attached in the central and macular area,

- when there was foveal adhesion but partial detachment temporally or nasally,

- when there was slight vitreous detachment between the optic disc and the fovea,

- when there was no posterior vitreous hyaloid visible at all (since it may be out of the antero/posterior OCT range).

Posterior vitreous with OCT was only confirmed as detached when the posterior vitreous hyloid was completely identified with distance to the retinal/macular surface. Still this could be a premacular lacuna, and information regarding the other methods (fundus biomicroscopy and ultrasound B examination) were included in the decision making.

As an accurate judgement of the posterior hyaloid can be very difficult, we believe that by using a combination of these methods we can guarantee the highest sensitivity and specificity currently achievable. We based our decision on the results of all three methods to achieve the highest specificity and sensitivity available. Patients in whom decisionmaking on state of vitreoretinal interface at baseline was not possible have not been included in the study.

Intravitreal drugs used in this study (see Table 2) included bevacizumab (Avastin ${ }^{\circledR}$ ) in 25 patients, ranibizumab
Table 1 Demographical data
61

$72 \pm 10.25(36-95)$

Female $\quad 32$

Male 29

$+1.29 \pm 2.0(-3.75$ to +8.75$)$

12 pseudophakic eyes

49 non pseudophakic eyes

47

8

6 
Fig. 1 US-B revealed. a No PVD before injection. $\mathbf{b}$ PVD after injection

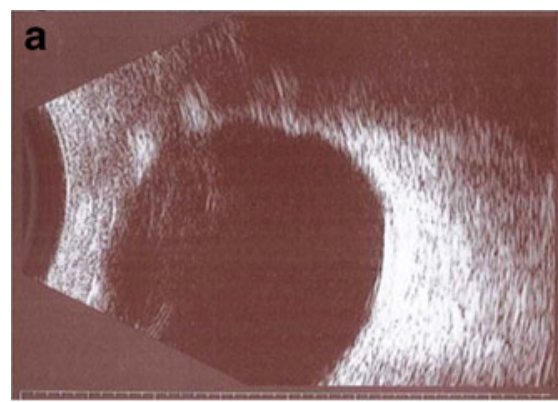

no PVD before injection

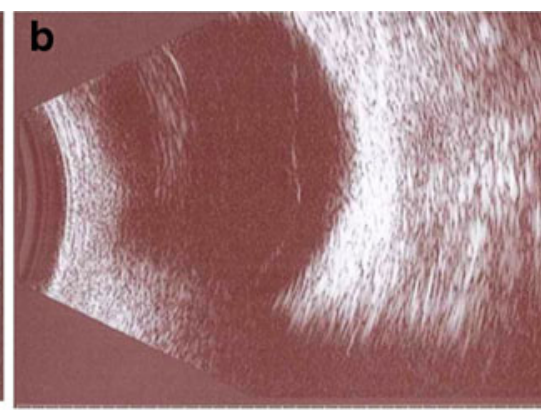

PVD after injection
(Lucentis ${ }^{\circledR}$ ) in 27 patients, and triamcinolone in six patients. Three patients received a combination of triamcinolone and bevacizumab. The injected volume of VEGF-inhibitors was $0.05 \mathrm{ml}$ and $0.1 \mathrm{ml}$ of triamcinolone respectively.

Regression analysis was performed to evaluate a possible influence of particular medication on the rate of induced PVD.

The intravitreal injections were performed under aseptic conditions according to the recommendations of the German Ophthalmologic Society.

Statistical analysis

Statistical analysis was performed using the software "Statistika" (Statistica software, StatSoft Inc., Tulsa, OK, USA) and Fisher's exact test.

\section{Results}

Fifteen of 61 patients $(24 \%)$ had a newly-diagnosed posterior vitreous detachment during the observation period. PVD was diagnosed after the first injection in 3/61 patients, after the second injection in $3 / 58$ patients, in $7 / 55$ patients after the third injection, and in $1 / 48$ patients after injection 5 and 1/47 after injection 6 (see Fig. 3). Seven of these 15 patients developed PVD after the third injection (Fig. 3). PVD occurred more often with increasing age $(p=0.0075$ comparing the 60-69 years age group and those aged 7079 years). As shown in Fig. 4, we observed only one PVD in the patients aged between 60 and 69 years, but six in the following decade, and eight in the age group from 80 to 95 years.

There was no statistical significance with regard to gender, underlying disease, left or right eye, or injected drug. No difference was observed with regard to the rate of PVD development comparing the subgroups of patients who had undergone intravitreal injections before entering the study, and patients who had not had any intravitreal injections before entering the study (see Fig. 4). The state of vitreomacular interface at baseline between these subgroups showed no significant difference using the three examination methods.

The level of concordance between the results of PVD seen by the three diagnostic methods was as follows: one patient showed PVD in all methods, two patients showed PVD in ultrasound B imaging only, two patients in OCT examination only, and two patients in fundus biomicroscopy only. Eight patients showed PVD in ultrasound B imaging as well as in fundus biomicroscopy.

In our study, three of the 15 patients who developed PVD were pseudophakic. There was no statistical significantly higher rate of PVD in pseuphakic eyes.

\section{Discussion}

Intravitreal drug injection has become the most important treatment of different macular diseases, and is widely used. Progression of several macular diseases seems to be affected by vitreous adhesion, and PVD may reduce macular edema or exudative age-related macular degeneration $[4,6,7,11]$.
Fig. 2 Cirrus-OCT. a Foveal vitreous adhesion. b Posterior hyaloid not visible/detectable after VCD

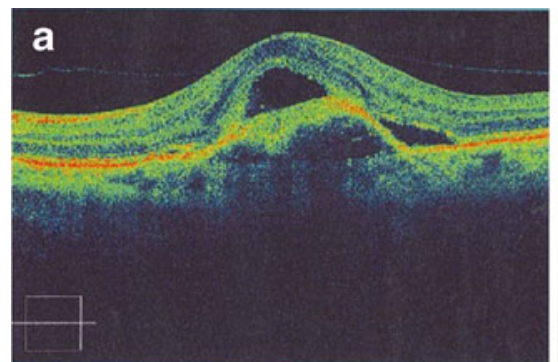

foveal vitreous adhesion

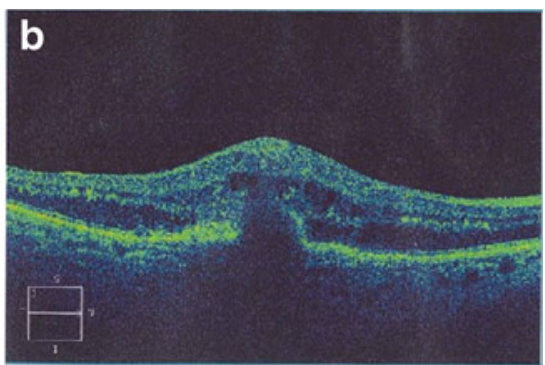

posterior hyaloid not visible / detectable after PVD 
Table 2 Distribution of intravitreal drugs administered

\begin{tabular}{llll}
\hline & Bevacizumab & Ranibizumab & Triamcinolone \\
\hline Patients $(n)$ & 25 & 27 & 9 \\
PVD $(n)$ & 7 & 6 & 2 \\
Number of injections & 3.0 & 3.17 & 2.5 \\
Mean follow up period [weeks] & 10.17 & 11.3 & 9.08 \\
\hline
\end{tabular}

The purpose of our study was to discover whether intravitreal injection induces posterior vitreous detachment, and any correlation with the number of injections or drug used. Sixtyone patients with attached posterior hyaloid were followed after one or more intravitreal injections over an 11.1-week period (mean) during which 15 eyes $(24 \%$ ) presented a PVD.

A limitation of our study is the relatively small number of enrolled patients and the lack of an age-matched control group. Therefore, our study's PVD rate must be compared to published data: regarding the prevalence of PVD, WeberKrause et al. published an overview of 703 patients from age 65 to $>-90$ years [15]. In those patients aged $65-69$ years the incidence of complete PVD (partial PVD) was $11 \%(17 \%)$, between 70 and 79 years $35 \%$ (9\%), between 80 and 89 years $46 \%$ (11\%), and over 90 years $49 \%$ (12\%) respectively.

Weber-Krause et al. reported a prevalence ranging from $27 \%$ to $61 \%$ in different age groups (60 to 90 years), which corresponds to an incidence of 1.3-1.6\% per year. However, they did not include patients with diabetic macular edema or proliferative retinal diseases in their study. Nevertheless, the high number of eyes developing a posterior vitreous detachment within a relatively short period after intravitreal injection in our study indicates that rather than being coincidental, PVD is induced by the intravitreal injection.

We observed a correlation between age and the incidence of PVD, noting a significant increase in PVD $(p=0.0075)$ when comparing the age groups of patients under and over 70 years.

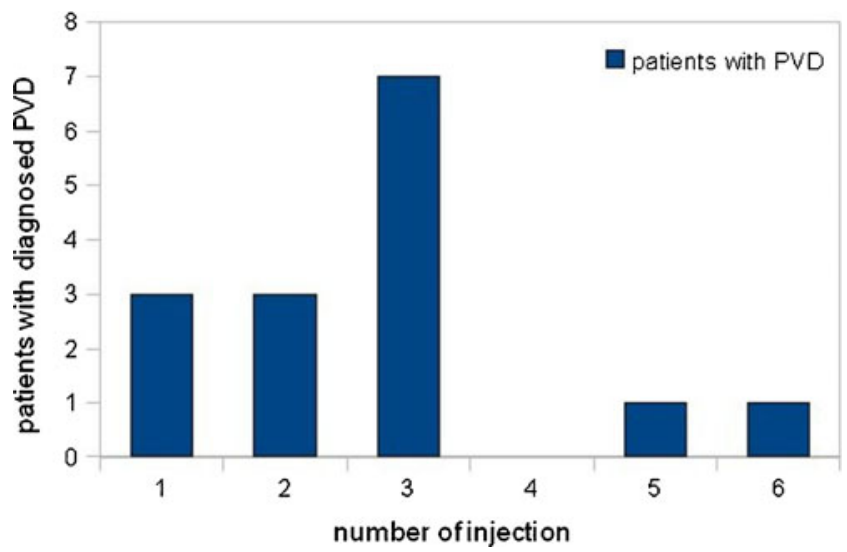

Fig 3 Correlation between occurence of PVD and number of injections
In the ocriplasmin study by Stalmans et al., $10.1 \%$ of 188 patients in the control group, receiving a sham-injection of $0.1 \mathrm{ml}$, developed a PVD [18]. It remains speculative wshether more injections may have created a higher rate of PVD in their study.

As stated in the literature, PVD is more likely to occur in myopic patients at a younger age [12, 17]. Vitreous volume and size of the eye might also play an important role on the development of PVD after intravitreal injection. Refraction error in our study seems to be insubstantial, as most of our patients were hyperopic (mean of $+1.3 \mathrm{dpt}$., $\mathrm{SD} \pm 2.0 \mathrm{dpt}$, range: from -3.75 to $+8.75 \mathrm{dpt}$.).

Axial length measurement in future studies would be helpful to figure out the influence of eye size on the rate of developing a PVD after intravitreal injection. Different injection volumes might also lead to a higher rate of PVD. Interestingly, none of the patients treated in this study with a combination of bevacizumab and triamcinolone developed a PVD despite the higher volume.

Although regression analysis in our study could not prove an influence on the development of a PVD regardless which type of drug or volume was used, the small sample size must be considered.

A further problem of the study is a mixture of different underlying diseases, which might themselves have an influence on the development of a PVD. In our study, one patient with CME after cataract surgery was included, and one patient with uveitic macular edema. In these two cases we detected PVD after injection. Inflammation or recent cataract extraction may promote a posterior vitreous detachment.

Another potential source of error is the posterior vitreous assesment. As macular surgery experience has shown us, it

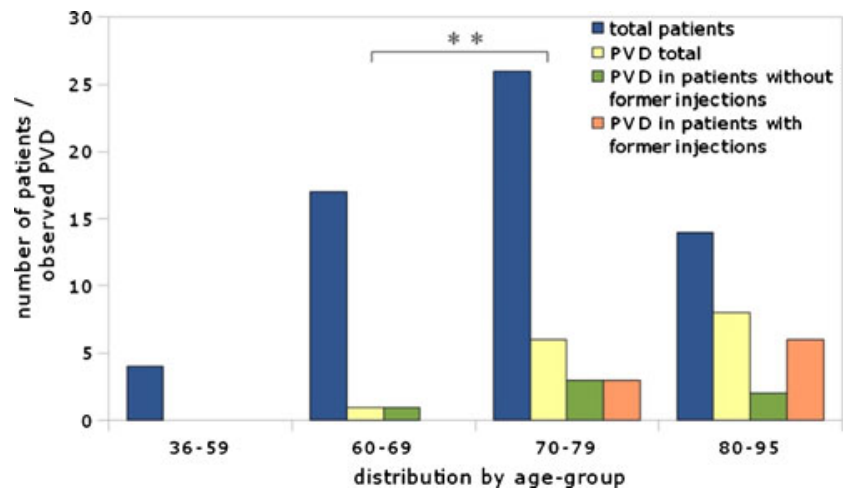

Fig 4 Occurence of PVD showing a correlation with the age of patients 
can be very hard to detect posterior vitreous detachment, and several studies have revealed that different diagnostic methods can deliver misleading data, with high variance in the reported data. During biomicroscopy, lacunae in the vitreous may simulate a PVD, although the posterior hyaloid remains attached to the retina. Furthermore, extensive liquefaction is not necessarily a sign of PVD $[2,10]$. Ultrasound seems to be the most reliable method for detecting PVD [15]. But as resolution is not very high, little or a partially-detached vitreous may not be visible. The high resolution of spectral-domain OCT delivers additional information on the vitreomacular interface and detects even very slight detachments or adhesions near the retina [3]. However, a completely attached vitreous may be missed, as well as a highly-detached posterior hyaloid, floating anterior to the OCT's limited axial scan area.

Since all these methods have their pros and cons, we used all three to provide the optimum available sensitivity at which to evaluate the posterior vitreous cortex situation correctly, and to minimize diagnostic errors.

Interesting is the fact that the $24 \%$ of PVD induction observed in this study resembles the rate achieved in a phase-III multicenter trial using intravitreal microplasmin in patients with vitreomacular traction syndroms (TG-MV007). However, that rate was achieved after just one injection, whereas a higher rate of up to $58 \%$ was described after three injections of microplasmin in a phase-II trial [14].

Our study suggests that the intravitreal injection itself may induce a PVD in patients with macular diseases. Older age seems to raise the incidence of PVD after intravitreal injection. Furthermore, a potential influence of the induced PVD on the underlying macular disease must be considered. As suggested in the literature, PVD may be associated with better regression of edema, fewer recurrences of CME, and it may even influence the recourse of age-related macular degeneration. To exactly determine this influence, more studies adressing this important issue are needed.

\section{Conclusion}

Intravitreal injection of commonly-used intravitreal drugs seems to induce posterior vitreous detachment, and may thereby influence the outcome of the underlying disease. Advanced age seems to be a predisposing factor.

Conflict of interest There is no conflict of interest. Graefe's Archive for Clinical and Experimental Ophthalmology is allowed to review any data if requested.

Open Access This article is distributed under the terms of the Creative Commons Attribution License which permits any use, distribution, and reproduction in any medium, provided the original author(s) and the source are credited.

\section{References}

1. Arai M, Yamamoto S, Mitamura Y, Sato E, Sugawara T, Mizunoya S (2009) Efficacy of vitrectomy and internal limiting membrane removal for macular edema associated with branch retinal vein occlusion. Ophthalmologica 223(3):172-176

2. Foos RY, Wheeler NC (1982) Vitreoretinal juncture. Synchysis senilis and posterior vitreous detachment. Ophthalmology 89 (12): $1502-1512$

3. Gallemore RP, Jumper JM, McCuen BW 2nd, Jaffe GJ, Postel EA, Toth CA (2000) Diagnosis of vitreoretinal adhesions in macular disease with optical coherence tomography. Retina 20(2):115-120

4. Gawecki M, Doroszkiewicz M, Rydzewski J (2010) Age related macular degeneration and presence of posterior vitreous detachment. Klin Ocz 112(7-9):210-212

5. Diabetic Retinopathy Clinical Research Network Writing Committee, Haller JA, Qin H, Apte RS, Beck RR, Bressler NM, Browning DJ, Danis RP, Glassman AR, Googe JM, Kollman C, Lauer AK, Peters MA, Stockman ME (2010) Vitrectomy outcomes in eyes with diabetic macular edema and vitreomacular traction. Ophthalmology 117(6):1087-1093.e3

6. Krebs I, Brannath W, Glittenberg C, Zeiler F, Sebag J, Binder S (2007) Posterior vitreomacular adhesion: a potential risk factor for exudative age-related macular degeneration? Am J Ophthalmol 144(5):741-746

7. Lopes de Faria JM, Jalkh AE, Trempe CL, McMeel JW (1999) Diabetic macular edema: risk factors and concomitants. Acta Ophthalmol Scand 77(2):170-175

8. Mojana F, Cheng L, Bartsch DU, Silva GA, Kozak I, Nigam N, Freeman WR (2008) The role of abnormal vitreomacular adhesion in age-related macular degeneration: spectral optical coherence tomography and surgical results. Am J Ophthalmol 146(2):218227

9. Nasrallah FP, Jalkh AE, Van Coppenolle F, Kado M, Trempe CL, McMeel JW, Schepens CL (1988) The role of the vitreous in diabetic macular edema. Ophthalmology 95(10):1335-1339

10. O'Malley P (1976) The pattern of vitreous syneresis - a study of 800 autopsy eyes. In: Irvine AR, O'Malley P (eds) Advances in vitreous surgery. Thomas, Springfield, pp 17-33

11. Ondeș F, Yilmaz G, Acar MA, Unlü N, Kocaoğlan H, Arsan AK (2000) Role of the vitreous in age-related macular degeneration. Jpn J Ophthalmology 44(1):91-93

12. Sebag J (1987) Ageing of the vitreous. Eye (Lond) 1(Pt 2):254-262

13. Schulze S, Hoerle S, Mennel S, Kroll P (2008) Vitreomacular traction and exudative age-related macular degeneration. Acta Ophthalmol 86(5):470-481

14. Stalmans P, Delaey C, de Smet MD, van Dijkman E, Pakola S (2010) Intravitreal injection of microplasmin for treatment of vitreomacular adhesion: results of a prospective, randomized, sham-controlled phase II trial (the MIVI-IIT trial). Retina 30(7):1122-1127

15. Weber-Krause B, Eckardt U (1996) Incidence of posterior vitreous detachment in eyes with and without age-related macular degeneration. An ultrasonic study. Ophthalmologe 93(6):660-665

16. Yamamoto S, Yamamoto T, Ogata K, Hoshino A, Sato E, Mizunoya S (2004) Morphological and functional changes of the macula after vitrectomy and creation of posterior vitreous detachment in eyes with diabetic macular edema. Doc Ophthalmol 109 (3):249-253

17. Yonemoto J, Ideta H, Sasaki K, Tanaka S, Hirose A, Oka C (1994) The age of onset of posterior vitreous detachment. GraefesArch Clin Exp Ophthalmol 232(2):67-70

18. Stalmans P, Benz MS, Gandorfer A, Kampik A, Girach A, Pakola S, Haller JA; MIVI-TRUST Study Group (2012) Enzymatic vitreolysis with ocriplasmin for vitreomacular traction and macular holes. N Engl J Med 367:606-615 